\title{
Energy Saving Research on Multi-effect Evaporation Crystallization Process of Bittern Based on MVR and TVR Heat Pump Technology
}

\author{
Deming Yang*, Bingqin Leng, Tao Li, Ming Li \\ College of Petrochemical Engineering, Changzhou University, Changzhou, China
}

\section{Email address:}

dmy216@163.com (Deming Yang),630308286@qq.com (Bingqin Leng), 296753999@qq.com (Tao Li), 784560752@qq.com (Ming Li)

${ }^{*}$ Corresponding author

\section{To cite this article:}

Deming Yang, Bingqin Leng, Tao Li, Ming Li. Energy Saving Research on Multi-effect Evaporation Crystallization Process of Bittern Based on MVR and TVR Heat Pump Technology. American Journal of Chemical Engineering. Vol. 8, No. 3, 2020, pp. 54-62.

doi: 10.11648/j.ajche.20200803.11

Received: April 22, 2020; Accepted: June 4, 2020; Published: June 17, 2020

\begin{abstract}
This work keeps an eye on the energy saving research on evaporation crystallization process of bittern. Based on the thermo sensitivity of solubility of various salts in bittern, the magnesium salts are purified. The conventional evaporation crystallization process used to separate the bittern demands high energy consumption and has low thermodynamic efficiency. Therefore, the multi-effect evaporation (MEE), thermal vapor recompression (TVR) heat pump and mechanical vapor recompression (MVR) heat pump technology were applied to the conventional evaporation crystallization process. The MVR and TVR technology can both make full use of the secondary steam heating materials that will save energy. In addition, Aspen Plus (Version 7.3) was used to simulate the processes of the electrolyte-containing system under the ELECNTRAL thermodynamic model. For the better evaluation of various evaporation crystallization processes, some important evaluation indexes, such as energy consumption, annual total cost (ATC) and exergy loss were chosen as objective functions. Compared with the double-effect evaporation crystallization process coupled with TVR heat pump technology, the results indicated that the double-effect evaporation crystallization process coupled with MVR heat pump technology can save energy consumption and ATC by $80.52 \%$ and $15.32 \%$ respectively. Furthermore, the MVR heat pump technology takes the lowest effective energy loss, which is a more competitive factor of evaporation crystallization process of bittern.
\end{abstract}

Keywords: Bittern, Evaporation Crystallization, MVR Heat Pump, TVR Heat Pump, MEE, ATC, Energy Saving

\section{Introduction}

Bittern, by-product of the seawater salt industry, contains high concentrations of valuable minerals such as potassium salts, magnesium salts and sodium salts [1]. Potassium salts are the main raw material of potassium-containing fertilizer, forasmuch it is in great demand in agriculture [2]. Magnesium salts mainly include magnesium chloride and magnesium sulfate, where magnesium can be extracted with electrolytic method [3]. Significant bittern resources are discharged into the sea or circulated in salt fields, which not only is a waste of resources but also destroys the ecological balance in the offshore waters [4]. Therefore, considering the competitiveness of market demands and environmental factors, it is necessary to separate the bittern with the expenditure of energy as low as possible. There are four kinds of the inorganic salts in the bittern system of this research, which are $\mathrm{MgSO}_{4}, \mathrm{NaCl}, \mathrm{KCl}$ and $\mathrm{MgCl}_{2}$ respectively. Smit et al [5] proposed the Anglo Research Nickel (ARNi) process, which showed that when it came to a certain temperature, the solubility of magnesium sulfate would be less than magnesium chloride so that hydrated magnesium sulfate precipitation could be obtained in a chloride solution system. Wang et al [6] found that when the temperature reached $75^{\circ} \mathrm{C}$, the magnesium sulfate became crystalline equilibrium so as to form magnesium sulfate monohydrate precipitation in a chloride solution system. The relationship between the solubility and temperature of the four inorganic salts in water is shown in Figure 1. The solubility characteristics of magnesium chloride show that when the temperature is higher 
than $50^{\circ} \mathrm{C}$, the thermal sensitivity of the solubility decreases. Furthermore, it appears a stable state firstly following by a downward trend as the temperature rising relentlessly. When the temperature is lower than $50^{\circ} \mathrm{C}$, the solubility is thermo sensitivity, which is positively correlated with the temperature. Therefore, the mix of sodium salts and potassium salts is precipitated as it cooled down below $50^{\circ} \mathrm{C}$. In pace with the temperature dropping incessantly, the magnesium chloride salt is precipitated thereafter. As a result of different temperature sensitivity of these salts, they could be separated by the evaporation crystallization process [7].

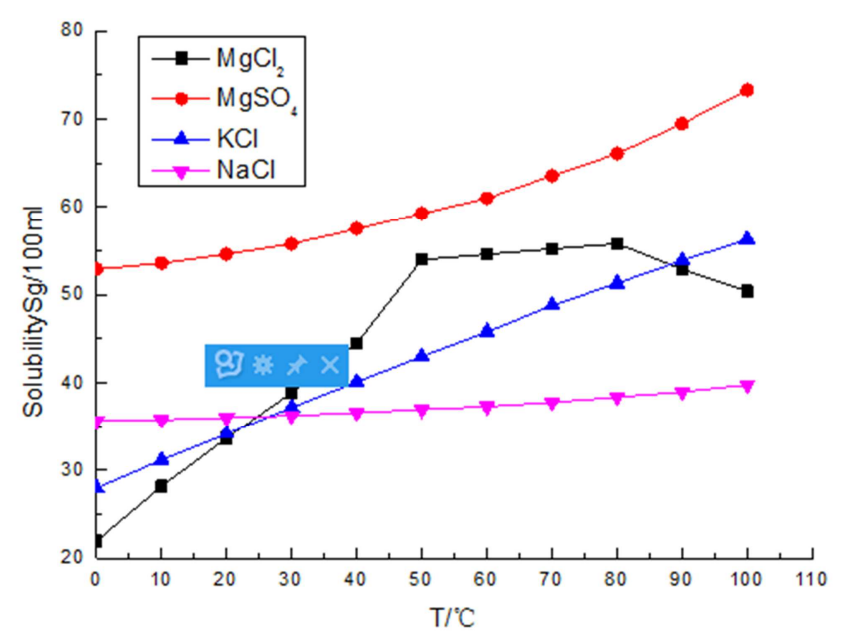

Figure 1. Solubility curve.

However, the conventional evaporation process used to separate the bittern demands high energy consumption and has low thermodynamic efficiency. In consideration of the situation, it is essential to work out an appropriate technology for lower energy consumption in evaporation. In the evaporator unit, the heat of the secondary steam generated from the evaporator is usually directly discharged as waste heat which can be used to preheat the feed. An important characteristic of MVR heat pump technology is the cycle of secondary steam [8]. MVR uses a mechanical fan, ordinarily driven by electricity, to recompress low pressure vapor to a slightly higher pressure and temperature. A five-effect milk evaporator train integrated with TVR was compared with a single effect evaporator integrated with MVR by Hanneman and Robertson [9], 55\% less fuel use in the MVR scheme reported. Another characteristic of MVR heat pump is the high energy efficiency. In distillation systems, MVR can directly compress top distillate vapor for use in the reboiler or can indirectly recovery heat from the distillate vapor using a separate working fluid before upgrade and use in the reboiler. These processing structures led to a step-change in energy integration [10]. TVR uses a thermo compressor with high pressure vapor to recompress low pressure vapor to a slightly higher pressure and temperature. TVR has found application in carbon capture processes to upgrade and recovery of waste, resulting in energy savings between 10 and 14\% [11]. Most of the related works revealed that multi-effect evaporation lowered the energy consumption cost by increasing the steam economy, which was to use the secondary steam generated by the previous effect as the heat source of the next effect. In desalination systems, multi-effect evaporation systems integrated with an absorption heat pump and vapor compression cycles can effectively synthesize to generate cooling and fresh clean water at $26 \%$ lower total cost [12].

In addition, the boiling point of the bittern is higher than the pure water solvent at the same pressure due to the existence of inorganic salts $[13,14]$. The boiling point elevation $\left(B P E\left[{ }^{\circ} \mathrm{C}\right]\right)$ is the temperature difference between the boiling point of the solution and the secondary steam [15]. The calculation formula is shown in equation (1).

$$
B P E=K_{b} \times n
$$

Where $\mathrm{K}_{\mathrm{b}}=M R T^{2} / \mathrm{r}$, which is the constant of the boiling point elevation; $M$ is the molecular weight of pure solvent (water); $\mathrm{R}$ is the general gas constant, and its value is 8.314; $T\left[{ }^{\circ} \mathrm{C}\right]$ is the value of the boiling point of the pure solvent, $r[\mathrm{~kJ} / \mathrm{kg}]$ is the heat of secondary vaporization, $n[\mathrm{kmol} / \mathrm{kg}]$ is the molar concentration of salt in solution.

The $B P E$ is also related to the pressure [16]. When the concentration of the solution is constant, it can also be calculated by using the Doulin's rule and empirical formula, which is displayed in equation (2).

$$
B P E=f \times B P E_{a}
$$

In the formula (2), $\mathrm{BPE}_{\mathrm{a}}\left[{ }^{\circ} \mathrm{C}\right]$ is the boiling point of the solution at normal pressure, $f$ is the pressure correction coefficient, as displayed by equation (3).

$$
f=0.0162\left[r^{2} /(T+273.15)\right]
$$

$B P E$ reduces the effective heat transfer temperature difference of the evaporator, which is also called the loss of the temperature difference caused by $B P E$.

The purpose of this work is to simulate and optimize the evaporation crystallization process to separate the bittern with Aspen Plus (version7.3). Furthermore, the multi-effect evaporation, heat integration, TVR and MVR technology were applied to the process to reduce the energy consumption and operating costs of the process substantially, so that theoretical basis for both the energy-saving renovation and the new installation of the plant could be proved with basic data collected.

\section{Simulation Rules and Evaluation Indexes}

\subsection{Simulation Rules and Property Method}

The processing mount of bittern was specified to be $45 \mathrm{t} / \mathrm{h}$ with the $\mathrm{NaCl}$ mass fraction of $6.5 \mathrm{wt} \%$, the $\mathrm{KCl}$ mass fraction of $3.15 \mathrm{wt} \%$, the $\mathrm{MgSO}_{4}$ mass fraction of $8.55 \mathrm{wt} \%$, the $\mathrm{MgCl}_{2}$ mass fraction of $8.25 \mathrm{wt} \%$ and that of water $73.55 \mathrm{wt} \%$ at ambient temperature and pressure. The product of the process was the $\mathrm{MgSO}_{4} \cdot \mathrm{H}_{2} \mathrm{O}$ with a purity of 0.995 and the $\mathrm{MgCl}_{2}$ with a purity of 0.93 . The bottom of the evaporator was 
heated with the saturated steam $(0.3 \mathrm{MPa})$. The utility cooling medium was the cooling water and frozen brine, whereas the inlet and outlet temperatures of cooling water was $33^{\circ} \mathrm{C}$ and $39^{\circ} \mathrm{C}$ respectively and those of frozen brine was $-15^{\circ} \mathrm{C}$ and $10^{\circ} \mathrm{C}$ respectively. Additional, the physical model was an important factor during the process. Normally, the ELECNRTL thermodynamic equation, a thermodynamic model based on the NTRL thermodynamic equation, is used for the treatment of electrolyte-containing systems like bittern. It is used to calculate the liquid phase activity coefficient with the Electrolyte NRTL equation and the gas phase fugacity coefficient with the Redlich-Kwong equation. In addition, it not only involves the effects between molecular and intermolecular, but also includes the effects between electrolyte and molecular as well as between electrolyte and electrolyte [17]. And in the evaporation crystallization process, the evaporator, compressor, thermal ejector, and heat exchanger were simulated with Flash2, Compr, MIX, and Heater models, respectively.

\subsection{Evaluation Indexes}

\subsubsection{Economics}

Annual total cost (ATC), taken as the comprehensive technical and economic evaluation indicators of the evaporation crystallization processes, is mainly composed of the capital investments $(\mathrm{CI})$ and the operation cost (OC). The CI mainly considers the fixed investment costs of equipment such as heat exchangers and steam compressors. Many small items, including pipes, valves and so on were not considered because of their small contribution to ATC calculations. The OC includes the costs of saturated vapor preheating the feed, electricity of the compressor and cooling water. The calculation formulas of ATC are shown in equations (4) to (11) $[18,19]$.

$$
\begin{aligned}
& A T C=O C+C I / \theta \\
& O C=O C_{S}+O C_{W}+O C_{M} \\
& C I=C I_{H}+C I_{C} \\
& C I_{H}=7296.0 \times A^{0.65} \\
& C I_{C}=0.9467 \times E_{M}^{0.62} \\
& O C_{S}=\varsigma_{S} \times Q_{S} / r_{S} \times 3600 \times 7200 / 1000 \\
& O C_{W}=\varsigma_{W} \times Q_{C} /(4.18 \times 6) \times 3600 \times 7200 / 1000 \\
& O C_{M}=\varsigma_{M} \times E_{M} \times 7200
\end{aligned}
$$

Where $O C_{S} 、 O C_{W}$ and $O C_{M}$ represent the operating costs of saturated steam, cooling water and electricity for compressor, respectively. $C I_{H}$ and $C I_{C}$ represent the investment costs of heat exchangers and compressors, respectively. $\theta$ [year] is the depreciation period of the equipment, which is taken as $8 . A\left[\mathrm{~m}^{2}\right]$ is the heat exchange area. $E_{M}[\mathrm{~kW} . \mathrm{h}]$ is power consumption of the compressor.
$\xi_{\mathrm{S}}[\$ /$ ton $] 、 \xi_{\mathrm{W}}[\$ /$ ton $]$ and $\xi_{\mathrm{M}}[\$ / k W . h]$ are the unit price of saturated steam, cooling water (or frozen brine) and electricity for compressor, namely $31.43,0.05$ (or 0.08 ) and 0.12 , respectively. $Q_{S}$ and $Q_{C}[\mathrm{~kW}]$ are the heating load and cooling load of the evaporator respectively.

\subsubsection{Exergy Efficiency}

Energy can not only be divided by quantity but also energy level. Effective energy is a thermodynamic state parameter to characterize the energy level. In a way, saving energy means saving exergy [20]. The effective energy loss of a process is greater, its thermodynamic efficiency is lower. Therefore, the magnitude of the effective energy loss can clearly reflect both the energy-saving features and the irreversible degree to energy conversion of the process [21].

The exergy of kinetic energy and potential energy of the fluid was ignored in order to simplify the calculation so that the change of effective energy in the evaporation process can be calculated as equation (12):

$$
\Delta B_{e v a}=\sum_{e x} n_{i}\left(H_{i}-T_{0} S_{i}\right)-\sum_{i n} n_{j}\left(H_{j}-T_{0} S_{j}\right)
$$

The net work consumed actually in the evaporation process is calculated using equation (13):

$$
W_{n e t}=Q_{s}\left(1-T_{0} / \mathrm{T}_{s}\right)-Q_{c}\left(1-T_{0} / T_{c}\right)
$$

Then the effective energy loss in the evaporation process is given by equation (14):

$$
E_{L}=W_{n e t}-\Delta B_{e v a}
$$

Where $\Delta B_{\text {eva }}[\mathrm{kJ} / \mathrm{h}]$ represents the change of effective energy in the evaporation process, $H[\mathrm{~kJ} / \mathrm{kg}]$ is the enthalpy of fluid at the inlet and outlet of turbine, $S[\mathrm{~kJ} / \mathrm{kg} . \mathrm{K}]$ is the entropy of fluid at the inlet and outlet of turbine, $\mathrm{T}_{0}$ [273.15K] is the ambient temperature, $T_{S}[\mathrm{~K}]$ is the temperature of the heating medium, $T_{C}[\mathrm{~K}]$ is the temperature of the cooling medium.

\section{Process Simulation}

\subsection{Conventional Evaporation Crystallization Process}

Figure 2 depicts conventional evaporation crystallization process for bittern which operates with two evaporators. The first evaporator and solid-liquid separation are used to extract $\mathrm{MgSO}_{4} \cdot \mathrm{H}_{2} \mathrm{O}$ crystals. The second evaporator and solid-liquid separation are used to gather the mixed salts of sodium and potassium salts. The bittern, is fed to the first evaporator with the filtrate generated from the II-effect evaporator to undergo boil up for evaporation. In order to improve the purity of magnesium chloride products, a part of sodium chloride crystals are precipitated at the temperature drop down to $45^{\circ} \mathrm{C}$ after the first evaporation crystallization process. And then, the $\mathrm{MgCl}_{2}$ crystals were separated out when the filtrate cooled down to $0^{\circ} \mathrm{C}$ after the second evaporation crystallization process. Both I-effect and II-effect systems are operated at 
atmospheric pressure. The simulation results are demonstrated in Table 1.

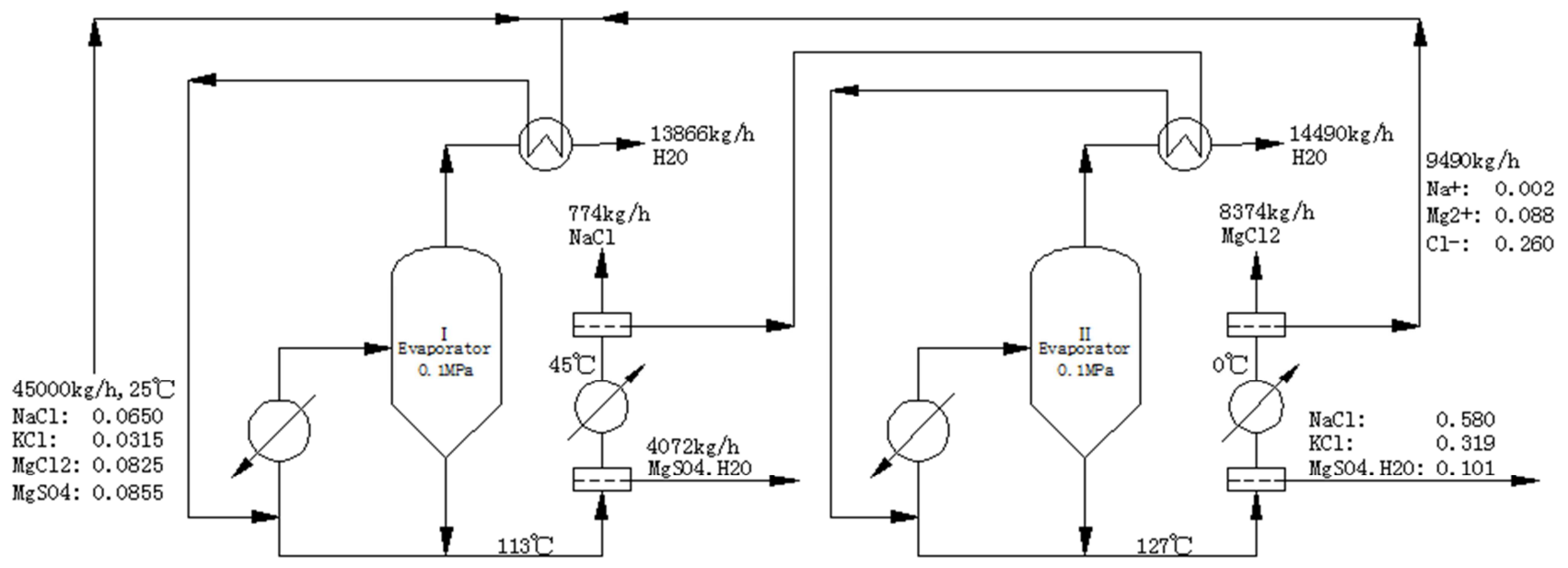

Figure 2. Conventional evaporation crystallization process.

Table 1. Simulation results of conventional evaporation crystallization process.

\begin{tabular}{lll}
\hline Item & $\begin{array}{l}\text { I-effect evaporation } \\
\text { system }\end{array}$ & $\begin{array}{l}\text { II-effect } \\
\text { evaporation }\end{array}$ \\
\hline Operating pressure $/ \mathrm{MPa}$ & 0.10 & 0.10 \\
Evaporation load $/ \mathrm{kW}$ & 9969.00 & 10062.60 \\
Secondary steam temperature $/{ }^{\circ} \mathrm{C}$ & 100 & 100 \\
Concentrate temperature $/{ }^{\circ} \mathrm{C}$ & 113 & 127 \\
Total heat transfer area $/ \mathrm{m}^{2}$ & 559.20 & 925.90 \\
Heating medium cost $/\left(\times 10^{4} \$ /\right.$ year $)$ & 372.93 & 376.44 \\
Coolant cost $/\left(\times 10^{4} \$ /\right.$ year $)$ & 36.61 & 47.77 \\
Energy loss $/ \mathrm{kJ} / \mathrm{h}$ & $6.16 \mathrm{E}+6$ & $7.27 \mathrm{E}+6$ \\
Total energy consumption $/ \mathrm{kW}$ & 20031.60 & \\
ATC $/\left(\times 10^{4} \$ /\right.$ year $)$ & 835.17 & \\
\hline
\end{tabular}

\subsection{Energy-saving Evaporation Crystallization Process}

In the conventional process, the energy consumption was still very high as it operated with a single effect, although the secondary steam was used to preheat the feed. Therefore, it is essential to make full use of the secondary steam and optimize the evaporation crystallization process to save energy. For this purpose, some energy-saving measures were applied to conventional process such as multi-effect evaporation (MEE),
TVR heat pump technology, and MVR heat pump technology.

\subsubsection{Double-effect Evaporation Crystallization Process}

Multi-effect evaporation lowers the energy consumption cost and increases the steam economy by the secondary steam treated as the heat source of the next effect [22]. There are two heat transfer conditions to be satisfied by the multi-effect evaporation process [23]. First, the temperature of the secondary steam generated from 1-effect evaporator must be 10 to $15^{\circ} \mathrm{C}$ higher than that of the next effect concentrated solution, which will determine the operating pressure of each effect. Second, the condensing load of the secondary steam generated from 1-effect evaporator needs to be slightly higher than the heating load of the next effect so as to define the evaporation load of each effect evaporator.

Figure 3 demonstrates the double-effect evaporation crystallization process. The I-effect evaporation system and II-effect evaporation system in the conventional evaporation process were changed into the double-effect evaporation process, which can greatly cut back the steam consumption of the conventional systems. The simulation results of the double-effect evaporation crystallization process are shown in Table 2.

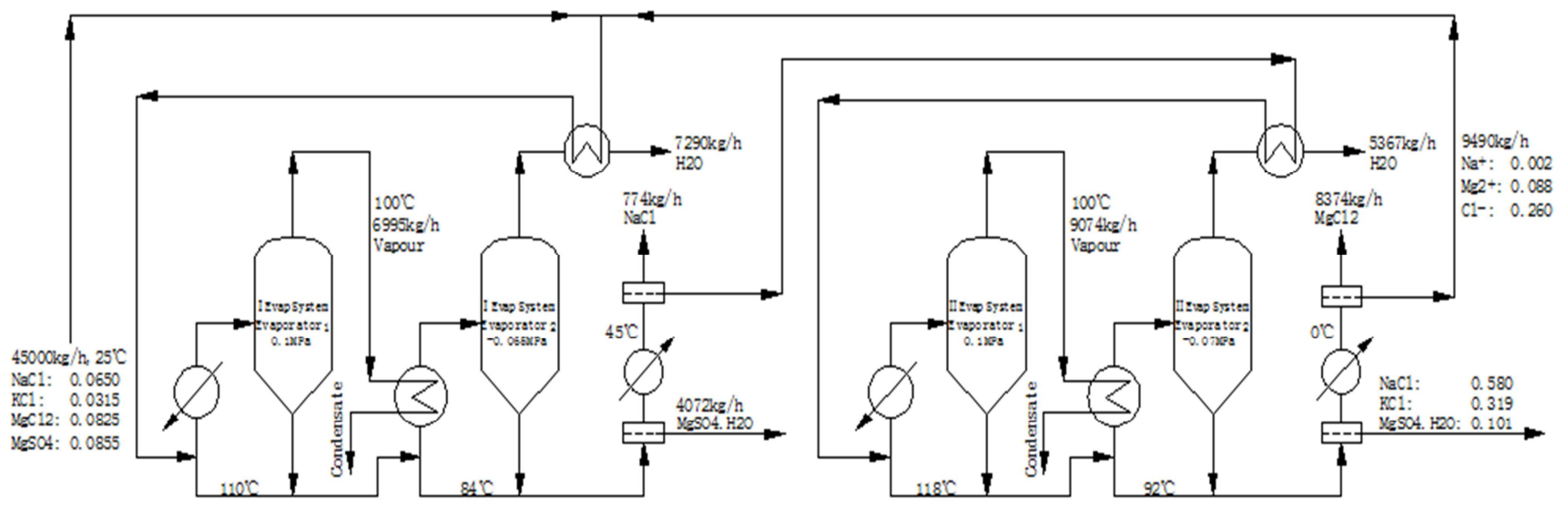

Figure 3. Double-effect evaporation crystallization process. 
Table 2. Simulation results of double-effect evaporation crystallization process.

\begin{tabular}{|c|c|c|c|c|}
\hline \multirow{2}{*}{ Item } & \multicolumn{2}{|l|}{ I-effect evaporation } & \multicolumn{2}{|l|}{ II-effect evaporation } \\
\hline & 1 effect evaporator & 2 effect evaporator & 1 effect evaporator & 2 effect evaporator \\
\hline Operating pressure $/ \mathrm{MPa}$ & 0.10 & -0.065 & 0.10 & -0.07 \\
\hline Secondary steam temperature $/{ }^{\circ} \mathrm{C}$ & 100 & 73 & 100 & 69 \\
\hline Concentrate temperature $/{ }^{\circ} \mathrm{C}$ & 110 & 84 & 118 & 92 \\
\hline Evaporation load/kW & 7345.60 & 3088.40 & 6661.00 & 3143.60 \\
\hline Total heat transfer area $/ \mathrm{m}^{2}$ & 532.50 & & 669.80 & \\
\hline Heating medium cost $/\left(\times 10^{4} \$ /\right.$ year $)$ & 274.80 & & 249.19 & \\
\hline Energy loss $/ \mathrm{kJ} / \mathrm{h}$ & $5.06 \mathrm{E}+6$ & & $3.86 \mathrm{E}+6$ & \\
\hline Total energy consumption $/ \mathrm{kW}$ & 14006.60 & & & \\
\hline $\mathrm{ATC} /\left(\times 10^{4} \$ /\right.$ year $)$ & 584.32 & & & \\
\hline
\end{tabular}

As shown in Tables 1 and 2 , it could be known that the energy consumption of the I-effect evaporation system of the double-effect evaporation crystallization process was reduced by $26.32 \%$ compared with the conventional process and that of the II-effect evaporation system was reduced by $33.80 \%$. What's more, the total energy consumption was reduced by $30.08 \%$, and the total ATC was saved by approximately $30.04 \%$. It was evident there are better economic advantages in the double-effect evaporation crystallization process.

\subsubsection{Double-effect Evaporation Crystallization Process Coupled with TVR Heat Pump}

In the double-effect evaporation crystallization process, the heat of secondary steam generated from the 2-effect evaporator cannot be fully utilized because of its low temperature, which is the main reason for high energy consumption. The Thermal Vapor Recompression (TVR) based on the heat pump is an effective method to increase the temperature of the secondary steam [24]. The high-pressure steam will form a high vacuum inside the venturi ejector under the action of its high flow rate. Following, the secondary steam is sucked in and mixed to form a higher temperature steam by compressed and heated [25]. The flow of the double-effect evaporation crystallization process coupled with TVR heat pump is shown in the Figure 4. The high-pressure steam $(1.7 \mathrm{MPa})$ is injected to the secondary steam to preheat the feed at higher temperature, which can reduce the amount of steam.

The main factor to the process is the mount of high-pressure steam used in the evaporation system. The higher the mount of high-pressure steam is utilized, the greater the temperature of the mixed steam and heating load of the ejection [26]. So the preheat temperature of the feed is higher, the low-pressure steam consumed by the 1-effect evaporator is less. Meanwhile, in order to save operating costs, the mixed steam pressure induced by the generator system was specified to be $0.25 \mathrm{MP}$. The simulation results of the double-effect evaporation crystallization process based on the TVR heat pump are shown in Table 3.

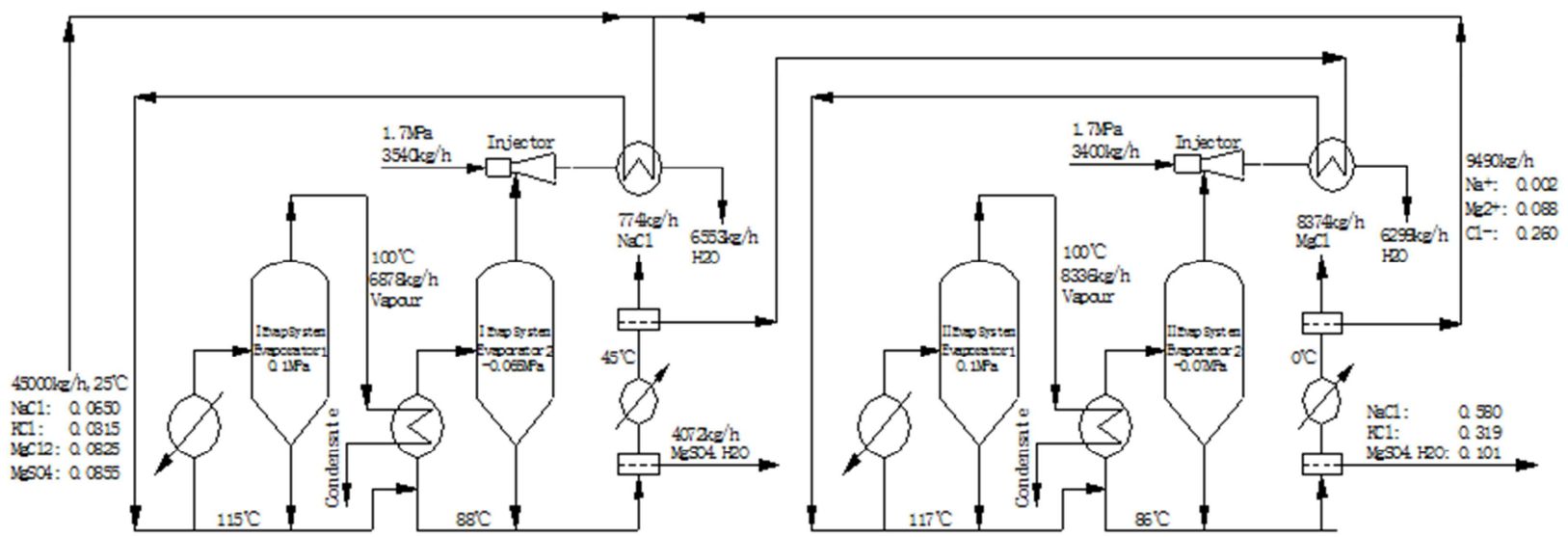

Figure 4. Double-effect evaporation crystallization process coupled with TVR heat pump.

Table 3. Simulation results of double-effect evaporation crystallization process coupled with TVR heat pump.

\begin{tabular}{|c|c|c|c|c|}
\hline \multirow{2}{*}{ Item } & \multicolumn{2}{|l|}{ I-effect evaporation } & \multicolumn{2}{|l|}{ II-effect evaporation } \\
\hline & 1 effect evaporator & 2 effect evaporator & 1 effect evaporator & 2 effect evaporator \\
\hline Operating pressure/MPa & 0.10 & -0.065 & 0.10 & -0.07 \\
\hline Secondary steam temperature $/{ }^{\circ} \mathrm{C}$ & 100 & 73 & 100 & 69 \\
\hline Secondary steam volume $/ \mathrm{kg} / \mathrm{h}$ & 6878 & 6553 & 8336 & 6299 \\
\hline High-pressure steam consumption $/ \mathrm{kg} / \mathrm{h}$ & 3540 & & 3400 & \\
\hline Ejection coefficient/ $\xi$ & 1.85 & & 1.85 & \\
\hline Pressure ratio & 0.147 & & 0.147 & \\
\hline
\end{tabular}




\begin{tabular}{|c|c|c|c|c|}
\hline \multirow{2}{*}{ Item } & \multicolumn{2}{|l|}{ I-effect evaporation } & \multicolumn{2}{|l|}{ II-effect evaporation } \\
\hline & 1 effect evaporator & 2 effect evaporator & 1 effect evaporator & 2 effect evaporator \\
\hline Concentrate temperature $/{ }^{\circ} \mathrm{C}$ & 115 & 88 & 117 & 86 \\
\hline Evaporation load/kW & 6099.30 & 3334.50 & 5862.50 & 3675.60 \\
\hline Total heat transfer area $/ \mathrm{m}^{2}$ & 701.0 & & 816.1 & \\
\hline Heating medium cost $/\left(\times 10^{4} \$\right.$ year $)$ & 131.09 & & 125.90 & \\
\hline Coolant cost $/\left(\times 10^{4} \$ /\right.$ year $)$ & 3.76 & & 10.74 & \\
\hline Energy loss $/ \mathrm{kJ} / \mathrm{h}$ & $4.13 \mathrm{E}+6$ & & $2.32 \mathrm{E}+6$ & \\
\hline Total energy consumption $/ \mathrm{kW}$ & 11961.80 & & & \\
\hline $\mathrm{ATC} /\left(\times 10^{4} \$ /\right.$ year $)$ & 273.79 & & & \\
\hline
\end{tabular}

According to the data in Tables 2 and 3, the total energy consumption and total ATC of the double-effect evaporation crystallization process coupled with TVR heat pump was reduced by $14.60 \%$ and $53.14 \%$ respectively as compared with the double-effect evaporation crystallization process. And the energy consumption of the I-effect evaporation system was reduced by $16.97 \%$, and $11.99 \%$ of the II-effect evaporation system. It could be seen that the double-effect evaporation crystallization process coupled with TVR heat pump was more economical than the double-effect evaporation crystallization process.

\subsubsection{Evaporation Crystallization Process Coupled with MVR Heat Pump}

Both the double-effect evaporation process and the TVR heat pump evaporation process require a certain amount of external steam, so neither of these two evaporation processes can achieve the best energy-saving effect. The Mechanical Vapor Recompression (MVR) is the most effective method to save energy nowadays by increasing temperature and energy level of the secondary steam [27]. The MVR heat pump technology was applied to the conventional crystallization process and double-effect evaporation crystallization process to explore its effect in energy saving.

(i). Single-effect Evaporation Crystallization Process Coupled with MVR Heat Pump

Based on the conventional process, the MVR heat pump technology adopts a compressor to improve the temperature and energy levels of the secondary steam so that the steam consumption reduces greatly leading to saving energy substantially [28]. The single-effect evaporation crystallization process coupled with MVR heat pump is shown in Figure 5.

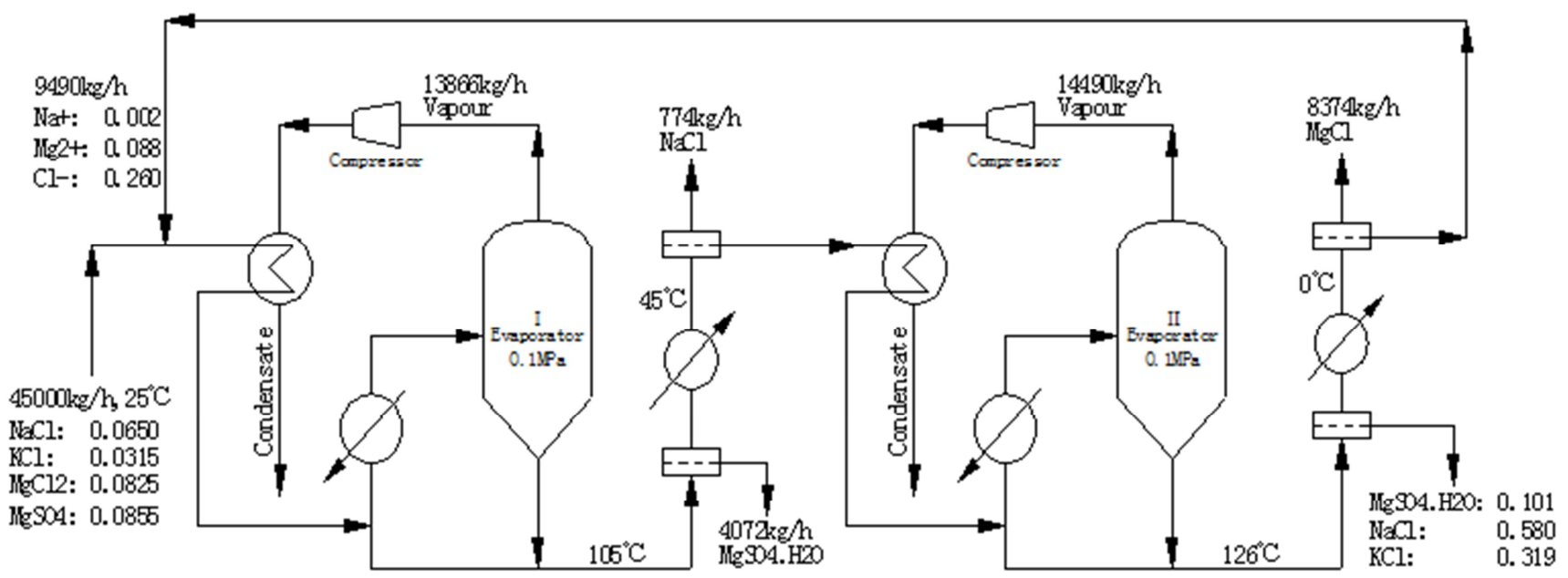

Figure 5. Single-effect evaporation crystallization process coupled with MVR heat pump.

If the feed temperature is in the bubble point of the MVR heat pump evaporation crystallization process, the latent heat released by the compressed secondary steam will be basically matched with the heat requirement of the evaporator [29]. In this process, since the feed is cold liquid, the evaporation system still needs supplying part of sensible heat for the feed to heat to concentrate. The heat transfer temperature difference between the compressed steam and the concentrated liquid is specified to be $10 \sim 15^{\circ} \mathrm{C}$, so as to determine the compression ratio of each compressor. The simulation results of the single-effect evaporation crystallization process coupled with MVR heat pump are presented in Table 4.
Table 4. Simulation results of single-effect evaporation crystallization process coupled with MVR heat pump.

\begin{tabular}{lll}
\hline Item & $\begin{array}{l}\text { I-effect } \\
\text { evaporation }\end{array}$ & $\begin{array}{l}\text { II-effect } \\
\text { evaporation }\end{array}$ \\
\hline Operating pressure/MPa & 0.10 & 0.10 \\
Pressure ratio & 1.80 & 2.80 \\
Compressor power consumption $/ \mathrm{kW}$ & 589.60 & 1196.90 \\
Secondary steam temperature $/{ }^{\circ} \mathrm{C}$ & 100 & 100 \\
Compressed steam temperature $/{ }^{\circ} \mathrm{C}$ & 213 & 253 \\
Supplementary heat load $/ \mathrm{kW}$ & 2614.20 & 506.30 \\
Total heat transfer area $/ \mathrm{m}^{2}$ & 490.80 & 470.30 \\
Heating medium cost $/\left(\times 10^{4} \$ /\right.$ year $)$ & 97.80 & 18.94 \\
Coolant cost $/\left(\times 10^{4} \$ /\right.$ year $)$ & 1.64 & 4.41 \\
\hline
\end{tabular}




\begin{tabular}{lll}
\hline Item & $\begin{array}{l}\text { I-effect } \\
\text { evaporation }\end{array}$ & $\begin{array}{l}\text { II-effect } \\
\text { evaporation }\end{array}$ \\
\hline Energy loss $/ \mathrm{kJ} / \mathrm{h}$ & $3.07 \mathrm{E}+6$ & $2.17 \mathrm{E}+6$ \\
Total energy consumption $/ \mathrm{kW}$ & 3120.50 & \\
$\mathrm{ATC} /\left(\times 10^{4} \$ /\right.$ year $)$ & 272.06 & \\
\hline
\end{tabular}

Based on the data in Tables 3 and 4, it could be seen that compared with the double-effect evaporation crystallization process coupled with TVR heat pump, the energy consumption of the I-effect evaporation system of the single-effect evaporation crystallization process coupled with MVR heat pump was reduced by $57.14 \%$, and that of the II-effect evaporation system was reduced by $91.36 \%$. Meanwhile the total energy consumption was reduced by $73.91 \%$, while the total ATC was similar, only with a decrease of about $0.63 \%$.

(ii). Double-effect Evaporation Crystallization Process Coupled with MVR Heat Pump

In the single-effect evaporation crystallization process coupled with MVR heat pump, the compressor was overload, which was the main reason of high power consumption. In case that the MVR heat pump coupled with the double-effect evaporation crystallization process, the amount in compression can be greatly reduced to lower the power consumption [30]. Therefore the energy consumption and ATC of the entire evaporation system will also be reduced. The flow of the double-effect evaporation crystallization process coupled with MVR heat pump is shown in Figure 6 and the simulation results of that are shown in the Table 5.

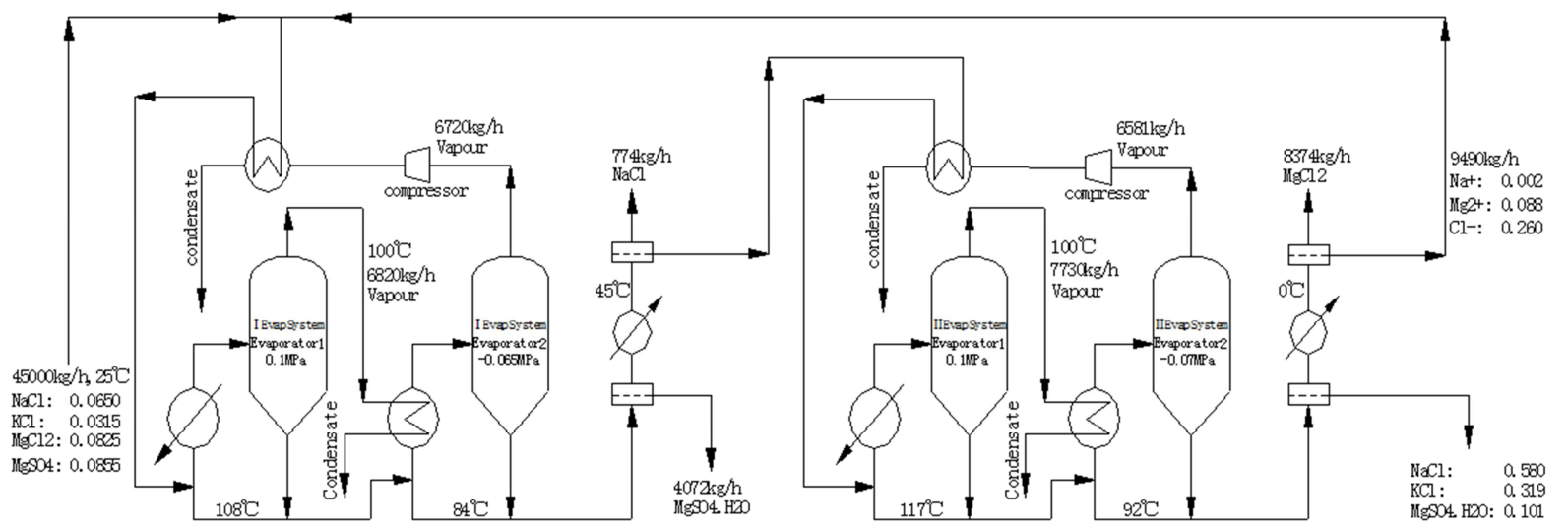

Figure 6. Double-effect evaporation crystallization process coupled with MVR heat pump.

Table 5. Simulation results of double-effect evaporation crystallization process coupled with MVR heat pump.

\begin{tabular}{llll}
\hline Item & I-effect evaporation & & II-effect evaporation \\
\hline & 1 effect evaporator & 2 effect evaporator & 1 effect evaporator evaporator \\
\hline Operating pressure $/ \mathrm{MPa}$ & 0.10 & -0.065 & 0.10 \\
Pressure ratio & 5.1 & & 7.0 \\
Compressor power consumption $/ \mathrm{kW}$ & 716.70 & & 961.30 \\
Secondary steam temperature $/{ }^{\circ} \mathrm{C}$ & 100 & 73 & 100 \\
Compressed steam temperature $/{ }^{\circ} \mathrm{C}$ & $/$ & 170 & $/$ \\
Supplementary heat load $/ \mathrm{kW}$ & 1764.40 & 3571.70 & 565.30 \\
Total heat transfer area $/ \mathrm{m}^{2}$ & 605.00 & & 562.40 \\
Heating medium cost $/\left(\times 10^{4} \$ /\right.$ year $)$ & 66.00 & & 21.14 \\
Coolant cost $/\left(\times 10^{4} \$ /\right.$ year $)$ & 1.37 & & 5.16 \\
Energy loss $/ \mathrm{kJ} / \mathrm{h}$ & $2.12 \mathrm{E}+6$ & & $1.12 \mathrm{E}+6$ \\
Total $\mathrm{energy} \mathrm{consumption} / \mathrm{kW}$ & 2329.70 & & 3895.30 \\
ATC $/\left(\times 10^{4} \$ /\right.$ year $)$ & 231.84 & & \\
\hline
\end{tabular}

According to the data shown in table 5, it could be seen that compared with the single-effect evaporation crystallization process coupled with MVR heat pump, the energy consumption of the double-effect evaporation crystallization process coupled with MVR heat pump was reduced by about $25.34 \%$, and ATC was saved about $14.78 \%$.

\subsection{Comparison of Important Technical and Economic Indexes for Various Processes}

In order to study the condition in the energy consumption and economy of various evaporation crystallization processes, the simulation results were summarized in Table 6 . The conventional evaporation crystallization process was labeled as Process 1, the double-effect evaporation crystallization process was labeled as Process 2, the double-effect evaporation crystallization process coupled with TVR heat pump was labeled as Process 3, the single-effect evaporation crystallization process coupled with MVR heat pump was labeled as Process 4, and the double-effect evaporation crystallization process coupled with MVR heat pump was labeled as Process 5. In order to facilitate the comparative analysis of various process indicators, the steam consumption and power consumption were unified into the standard coal [31].

In the conventional evaporation crystallization process, the total energy consumption was still rather high; although the temperature of the secondary steam used to preheat the 
material was relatively high. As in the double-effect evaporation crystallization process, the heat of secondary steam could not be fully applied because of its low temperature, which was the main reason for high energy consumption. And for the TVR heat pump technology, although the secondary steam could be fully used at the low temperature level, it still came at the expense of high-pressure steam at high temperature. Only in the process with MVR heat pump technology, the secondary steam could be fully used in low temperature and energy level at a lower cost. Therefore, the MVR heat pump evaporation crystallization process was the most economical in this work.

Table 6. Summary of main process indicators for various evaporation processes.

\begin{tabular}{|c|c|c|c|c|c|}
\hline Item & Process 1 & Process 2 & Process 3 & Process 4 & Process 5 \\
\hline Energy consumption/ ton/year & 18734.30 & 13099 & 7709.60 & 6961.20 & 5975.60 \\
\hline Heating medium cost $/\left(\times 10^{4} \$ /\right.$ year $)$ & 749.37 & 523.99 & 256.99 & 116.74 & 87.14 \\
\hline Coolant cost $/\left(\times 10^{4} \$ /\right.$ year $)$ & 84.39 & 58.52 & 14.50 & 6.05 & 6.53 \\
\hline Equipment depreciation $/\left(\times 10^{4} \$ /\right.$ year $)$ of standard coal $/$ year & 1.41 & 1.81 & 2.30 & 3.21 & 3.46 \\
\hline Energy loss $/\left(\times 10^{6} \mathrm{~kJ} / \mathrm{h}\right)$ & 13.43 & 8.92 & 6.45 & 5.24 & 3.24 \\
\hline $\mathrm{ATC} /\left(\times 10^{4} \$ /\right.$ year $)$ & 835.17 & 584.32 & 273.79 & 272.06 & 231.84 \\
\hline
\end{tabular}

As depicted in Table 6, it could be seen that compared with Process 1, in terms of the energy consumption, Process 2 to Process 5 saved energy by about $30.08 \%, 58.85 \%, 62.84 \%$, and $68.10 \%$, respectively. And in terms of ATC, the process 2 to Process 5 saved by $30.04 \%, 67.22 \%, 67.42 \%$ and $72.24 \%$ respectively.

\section{Conclusion}

In the evaporation crystallization process, a large amount of thermal energy was required for the excess water, and it was difficult to fully use the waste heat of secondary steam. To this end, the multi-effect evaporation, TVR heat pump and MVR heat pump technology were applied to the evaporation crystallization process for separating the bittern in this study. The various processes were simulated and optimized under the ELENCRTL thermodynamic calculation model with Aspen Plus software. In the conventional process the energy consumption was about $445.2 \mathrm{~kW}$ per ton and the ATC of the device with a processing capacity $(45 \mathrm{t} / \mathrm{h})$ of bittern was about 8.35 million dollars. In the double-effect evaporation crystallization process, the energy consumption and the ATC were reduced by $30.08 \%$ and $30.04 \%$ respectively compared with the conventional process due to the full utilization of the secondary steam generated from 1-effect evaporator. In the double-effect evaporation crystallization process coupled with TVR heat pump, all the secondary steam was made good use of, so the energy consumption and the ATC were lower than the conventional double-effect evaporation process by $14.60 \%$ and $53.14 \%$ respectively. However, it still came at the cost of consuming a certain amount of high-temperature steam. In the MVR heat pump evaporation crystallization process, the secondary steam was recycled at a relatively low cost, so the economic advantage was particularly obvious. Compared with the double-effect evaporation crystallization process coupled with TVR heat pump, the energy consumption of the single-effect evaporation crystallization process coupled with MVR heat pump and the double-effect evaporation crystallization process coupled with MVR heat pump has been reduced by $73.91 \%$ and $80.52 \%$ respectively, and the ATC has been saved by $0.63 \%$ and $15.32 \%$, respectively. In the MVR heat pump evaporation crystallization process, since the heat exchange temperature difference of the evaporator was smaller, the effective energy loss in the evaporation process was also the least among these processes.

\section{References}

[1] Ayoub GM, Hamzeh A, Semerjian L. Post treatment of tannery wastewater using lime/bittern coagulation and activated carbon adsorption. DESALINATION. Vol. 273, No. 2-3, 2011, pp. 359-365.

[2] Niu XS, Wang AJ, Zheng MP. The consumption law and demand forecast of potash in China. China Mining. Vol. 28, 2019, pp. 6-12.(In Chinese)

[3] Alamdari A, Rahimpour MR, Esfandiari N, Nourafkan E. Kinetics of magnesium hydroxide precipitation from sea bittern. Chemical Engineering and Processing: Process Intensification. Vol. 47, No. 2, 2008, pp. 215-221.

[4] Di Palma L, Verdone N, Chianese A, Di Felice M, Merli C, Petrucci E, et al. Treatment of wastewater with high inorganic salts content. ENVIRON ENG SCI. Vol. 19, No. 5, 2002, pp. 329-339.

[5] Smit JT, Steyl JDT. Leaching process in the presence of hydrochloric acid for the recovery of a value metal from an ore: EP1809778B1 [P]. 2006-4-27.

[6] Wang H, Ding WZ, Tan DS. Crystalline equilibrium of magnesium sulfate in chloride solutions. HYDROMETALLURGY OF CHINA. Vol. 36, No. 1, 2017, pp. 50-53.(In Chinese)

[7] Lefebvre O, Moletta R. Treatment of organic pollution in industrial saline wastewater: A literature review. WATER RES Vol. 40, No. 20, 2006, pp. 3671-3682.

[8] Gao X, Ma Z, Ma J, Yang L. Application of Three-Vapor Recompression Heat-Pump Concepts to a Dimethylformamide-Water Distillation Column for Energy Savings. ENERGY TECHNOL-GER. Vol. 2, No. 3, 2014, pp. 250-256.

[9] Hanneman H, Robertson LJ. Heat recovery systems. In: Energy use dairy process. Brussels, Belgium: International Dairy Federation, 2005. 
[10] Modla G, Lang P. Heat pump systems with mechanical compression for batch distillation. ENERGY. Vol. 62, 2013, pp. 403-417.

[11] Reddick C, Sorin M, Sapoundjiev H, Aidoun Z. Carbon capture simulation using ejectors for waste heat upgrading. ENERGY. Vol. 100, 2016, pp. 251-261.

[12] Janghorban Esfahani I, Kang YT, Yoo C. A high efficient combined multi-effect evaporation-absorption heat pump and vapor-compression refrigeration part 1: Energy and economic modeling and analysis. ENERGY. Vol. 75, 2014, pp. 312-326.

[13] Yue C, Wang B, Zhu B. Thermal analysis for the evaporation concentrating process with high boiling point elevation based exhaust waste heat recovery. DESALINATION. Vol. 436, 2018, pp. 39-47.

[14] Han D, He W, Yue C, Pu W, Liang L. Analysis of energy saving for ammonium sulfate solution processing with self-heat recuperation principle. APPL THERM ENG. Vol. 73, No. 1, 2014, pp. 641-649.

[15] Alasfour FN, Abdulrahim HK. The effect of stage temperature drop on MVC thermal performance. DESALINATION. Vol. 265, No. 1-3, 2011, pp. 213-221.

[16] Chen LF, Zhu HB, Xu L. Simulation of thermo-recompression evaporation in purified brine. INORGANIC CHEMICALS INDUSTRY. Vol. 48, No. 4, 2016, pp. 53-56.(In Chinese)

[17] Boukhalfa N, Méniai A. Thermodynamic Modeling of Aqueous Electrolytes Type 2-1. Procedia Engineering. Vol. 148, 2016, pp. 1121-1129.

[18] Yang D, Yin Y, Wang Z, Zhu B, Gu Q. Multi-Effect Evaporation Coupled with MVR Heat Pump Thermal Integration Distillation for Separating Salt Containing Methanol Wastewater. Energy and Power Engineering. Vol. 9, No. 12, 2017, pp. 772-785.

[19] Gao X, Gu Q, Ma J, Zeng Y. MVR heat pump distillation coupled with ORC process for separating a benzene-toluene mixture. ENERGY. Vol. 143, 2018, pp. 658-665.

[20] Nafey AS, Fath HES, Mabrouk AA. Thermo-economic investigation of multi effect evaporation (MEE) and hybrid multi effect evaporation--multi stage flash (MEE-MSF) systems. DESALINATION. Vol. 201, No. 1-3, 2006, pp. 241-254.
[21] Darwish M. A., Hisham El-D. The heat recovery thermal vapor-compression desalting system: a comparison with other thermal desalination processes. Applied Energy. Vol. 416, No. 6, 1995, pp. 523-537.

[22] Zhao D, Xue J, Li S, Sun H, Zhang Q. Theoretical analyses of thermal and economical aspects of multi-effect distillation desalination dealing with high-salinity wastewater. DESALINATION. Vol. 273, No. 2-3, 2011, pp. 292-298.

[23] El Dessouky H, Alatiqi I, Bingulac S, Ettouney $H$. Steady--State Analysis of the Multiple Effect Evaporation Desalination Process. CHEM ENG TECHNOL. Vol. 21, No. 5, 1998, pp. 437-451.

[24] Kamali RK, Abbassi A, Sadough Vanini SA. A simulation model and parametric study of MED--TVC process. DESALINATION. Vol. 235, 2009, pp. 340-351.

[25] Al-Mutaz IS, Wazeer I. Development of a steady-state mathematical model for MEE-TVC desalination plants. DESALINATION. Vol. 351, 2014, pp. 9-18.

[26] Kouta A, Al-Sulaiman F, Atif M, Marshad SB. Entropy, exergy, and cost analyses of solar driven cogeneration systems using supercritical $\mathrm{CO}_{2}$ Brayton cycles and MEE-TVC desalination system. ENERG CONVERS MANAGE. Vol. 115, 2016, pp. 253-264.

[27] Hayani Mounir S, Feidt M, Vasse C. Thermoeconomic study of a system for pollutant concentration with mechanical vapour compression. APPL THERM ENG. Vol. 25, No. 2-3, 2005, pp. 473-484.

[28] Aly NH, El-Figi AK. Mechanical vapor compression desalination systems--a case study. DESALINATION. Vol. 158, No. 1, 2003, pp. 143-150.

[29] Elvis A, Nidret I, Zdravko K, Ignacio E. Simultaneous optimization and heat integration of evaporation systems including mechanical vapor recompressions and background process. ENERGY. Vol. 158, 2018, pp. 1160-1191.

[30] Liang L, Han D, Ma R, Peng T. Treatment of high-concentration wastewater using double-effect mechanical vapor recompression. DESALINATION. Vol. 314, 2013, pp. 139-146.

[31] None. GB/T 50441-2007 Standard for calculation of energy consumption in petrochemical engineering design. China Planning Press, 2008. (In Chinese). 